\title{
LA AURORA DE LA ETERNIDAD. LAS FIGURAS DEL INSTANTE EN LA ESTRELLA DE LA REDENCIÓN DE FRANZ ROSENZWEIG
}

\author{
ÁNGEL ENRIQUE GARRIDO-MATURANO \\ CONICET-Argentina
}

\begin{abstract}
RESUMEN: El artículo analiza el instante en La Estrella de la Redención de Franz Rosenzweig. Primero deconstruye y articula los distintos estratos significativos de la noción de instante en los tres libros de la segunda parte de esta obra (Creación, Revelación y Redención) como figuras de la temporalización de la eternidad; y en la tercera parte como figura de la eternización de la temporalidad. Luego reconstruye la esencia del instante como lapso de intersección entre tiempo y eternidad de carácter reiterable y trascendental. Finalmente indica en qué medida las distintas figuras del fenómeno guardan una significación religiosa pre-confesional.
\end{abstract}

PALABRAS CLAVE: instante; tiempo; eternidad; Rosenzweig.

\section{The Dawn of Eternity. The Faces of the Moment in Franz Rosenzweig's The Star of Redemption}

ABSTRACT: The article analyzes the Moment in Franz Rosenzweig's The Star of Redemption. First it deconstructs and articulates the meaningful strata within the notion of Moment in the three books of the second part of The Star (Creation, Revelation, and Redemption) as faces of the temporalization of eternity and in the third part as the face of the eternalization of temporality. Secondly, the article reconstructs the essence of the Moment as the intersection lapse between time and eternity, which has a repeatable and transcendental character. Finally, it shows the extent in which the different faces of the phenomenon exhibit a religious pre-confessional significance.

KEY WORDS: Moment; Time; Eternity; Rosenzweig

\section{INTRODUCCIÓN}

Las páginas que aquí comienzan ofrecen un análisis específico ${ }^{1}$ de la cuestión del instante ${ }^{2}$ en La Estrella de la Redención de Franz Rosenzweig. El

1 No es éste, pues, un estudio general de la obra capital del filósofo de Kassel. Tampoco dispongo aquí de espacio para una introducción a La Estrella que no sólo se contente con vagas generalidades. A quien guste de adentrarse en la estructura del libro le sugiero dos obras clásicas, que aún hoy continúan siendo las mejores elucidaciones (e interpretaciones) filosóficas de La Estrella. Me refiero, en primer lugar, a: Mosès, S., System und Offenbarung. Die Philosophie Franz Rosenzweigs, Wilhelm Fink, München 1985. En segundo, hay que mencionar otro libro notable, del que ha salido hace muy poco una tercera edición, revisada y ampliada. Se trata de: CASPER, B., Das dialogische Denken. Franz Rosenzweig. Ferdinand Ebner und Martin Buber, Aber, Freiburg/München ${ }^{3} 2017$, pp. 62-193. En nuestro idioma se puede recordar el excelente estudio introductorio del traductor al español de La Estrella: García-BARó, M., «Introducción», en: Rosenzweig, F., La Estrella de la Redención, Sígueme, Salamanca 1997, pp. 11-39; sigla ER. Finalmente, Garrido-Maturano, Á., La Estrella de la Esperanza. Introducción a La Estrella de la Redención de Franz Rosenzweig desde una perspectiva fenomenológica, Academia Nacional de Ciencias, Buenos Aires 2000.

2 Hasta donde mi conocimiento alcanza hay sólo dos trabajos que se dedican a la cuestión del instante en La Estrella, pero desde perspectivas muy diferentes a la del presente 
análisis está al servicio de tres objetivos concatenados. El primero se propone deconstruir ${ }^{3}$, pero también articular, los distintos estratos significativos de la noción de instante en La Estrella, en particular en cada uno de los libros (Creación-Revelación-Redención) que componen la segunda parte de esta obra y en la introducción a la tercera parte. Este objetivo parte de la hipótesis según la cual no existe una significación única del término "Augenblick» («instante») en el libro capital de Franz Rosenzweig. Antes bien, cada uno de sus estratos significativos resulta o bien de la dirección diferente (desde el pasado, presente o futuro) desde la cual la eternidad se temporaliza en el presente, o bien del modo en que el tiempo se eterniza. Dichos estratos, por supuesto, no se hallan desconectados unos de otros, sino que la deconstrucción debe elucidar cómo cada uno de ellos constituye la condición trascendental de posibilidad del siguiente. Si este primer objetivo deconstructivo acentúa las diferencias en los significados y funciones del término «instante» en La Estrella, el segundo reconstructivo intentará discriminar y re-con-figurar la esencia común de cada uno de los estratos. Parte para ello de una segunda hipótesis, a saber, aquella que considera que la índole del instante rosenzweiguiano en todas sus formas radica en ser un punto de intersección entre tiempo y eternidad caracterizado por la «reiterabilidad» $\mathrm{y}$ «trascendentalidad» de tales intersecciones. Finalmente, el último objetivo procurará explicitar en qué medida la esencia del instante nos permite pensar que el fenómeno guarda una significación religiosa pre-confesional, concebida como vínculo con lo Absoluto.

Una breve aclaración metodológica evitará posibles malentendidos. Este estudio no es ni quiere ser una investigación filológica y erudita sobre el instante en La Estrella, lo cual, por cierto, sería un trabajo muy meritorio. Menos aún es un estudio sobre las fuentes judías del autor. No se propone, entonces, ni exponer de modo exhaustivo todas las referencias al instante en la obra de Rosenzweig, ni explicitar sus raíces culturales en el judaísmo, ni tampoco discernir sus

artículo. Froman, Wayne J., «Rosenzweig and Heidegger on "the moment" ("der Augenblick")», en: Schmied-Kowarzik, W. (ed.), Franz, Rosenzweigs "neues Denken»-Band I: Selbstbegrenzendes Denken: in Philosophos, Alber, Freiburg/München 2006, pp. 228-246. Se trata -más que de un estudio específico sobre el instante en Rosenzweig- de una presentación general de la idea de instante en La Estrella puesta al servicio de la siguiente pregunta: "¿Puede el estatus del momento, "der Augenblick" en La Estrella de la Redención arrojar más luz sobre el itinerario de Heidegger?» (p. 239). Excelente es el artículo de Bensussan, G., «Instant éthique et raison politique», en: Schmied-KowarziK, W., op. cit., pp. 459-469. Bensussan, más que desarrollar un análisis sistemático de las distintas figuras del instante en La Estrella, se concentra en destacar algunos rasgos del fenómeno, a saber: su carácter de acontecimiento discontinuo, denso, diacrónico e imprevisible, para extraer de allí consecuencias relativas a la imposibilidad de la política de responder por sí misma a los desafíos que el instante provoca..

3 Por «deconstruir» entiendo aquí des-componer el concepto de instante y mostrar la función específica que cada uno de sus estratos tiene en el tramado de la arquitectura de $L a$ Estrella. 
implicancias teológicas. Por el contrario, se trata de un estudio que aspira a ser filosófico, en la medida en que distingue distintos estratos significativos del fenómeno en el texto rosenzweiguiano, para, a partir de allí, mostrar cuál es la esencia del instante y en qué medida esta esencia remite al acaecimiento de lo Absoluto en el tiempo. En tanto estudio filosófico se rige por un método que podemos denominar hermenéutico, crítico y fenomenológico. Es hermenéutico no porque desarrolle una lectura de su tema en función de una cierta teoría de interpretación textual. Antes bien, de lo que aquí se trata — acudiendo a una expresión de Heidegger - es de lo que podríamos llamar una hermenéutica de la facticidad. Es decir, el análisis es hermenéutico en cuanto, por su mismo modo de darse, el instante requiere que se lo explicite en función de la estructura hermenéutica de "algo como algo» para que puedan salir a la luz la plenitud de sus significaciones. Es, además, fenomenológico; y ello en dos sentidos. En primer lugar, porque se centra en la descripción de la esencia de la experiencia del instante, esto es, en la descripción de aquellas condiciones que hacen posible que el instante acaezca en cada una de sus figuras tal como lo hace y signifique tal cual él significa. Pero, en segundo lugar, y fundamentalmente, porque la fenomenología encuentra la esencia de las vivencias en una correlación entre el modo en que me sale al encuentro lo que se da y el modo en que voy hacia ello y lo asumo. Precisamente en cuanto este trabajo intenta asir la esencia del instante en el marco de una correlación entre un acto del existente y un acontecimiento del mundo, él permanece fiel a este principio fenomenológico correlacional. Finalmente, en cuanto se trata de un trabajo que se mantiene en el ámbito de la filosofía, prescinde de la fe en toda revelación positiva determinada y le interesa, más que narrar cómo vive el instante el judío o el cristiano, describir en qué medida el fenómeno en sus distintas figuras es susceptible de ser experimentado por todo hombre en su condición de tal. Este estudio -así concebido- ies un estudio rosenzweiguiano? En cierta medida no, puesto que se aparta conscientemente tanto de la fe judía desde la que escribe Rosenzweig, cuanto de su filosofía del cristianismo y del judaísmo, para apropiarse de las significaciones latentes en su texto, reconstruirlas desde una perspectiva preconfesional y, así, explicitar de qué manera todo hombre qua hombre puede experimentar el instante y qué implica esa experiencia crucial. Pero, en otra medida, tal vez más fundamental, quizás sí lo sea. Y ello porque, en última instancia, su perspectiva de análisis coincide con la intención fundamental de la obra capital de Rosenzweig, tal cual el propio autor lo declara en El nuevo pensamiento, cuando afirma: «La Estrella no es para nada un "libro judío" (...). Tampoco tiene la pretensión de ser una filosofía de la religión. (...). Antes bien, es meramente un sistema de filosofía ${ }^{4}$.

4 Rosenzweig, F., El nuevo pensamiento, trad. A. Garrido-Maturano, Adriana Hidalgo, Buenos Aires 2005, p. 14. 


\section{LA TEMPORALIZACIÓN DE LA ETERNIDAD EN EL INSTANTE}

\subsection{El sentido del instante en la creación}

La Creación mienta el acontecimiento por el cual Dios y mundo dejan de ser los puros conceptos lógicos (ideas, en el sentido kantiano del término) sin vínculo entre sí, tal cual habían sido construidos al final de la primera parte de La Estrella, para revelarse como realidades efectivamente existentes ya siempre en relación mutua. Ahora bien, Dios habrá de revelarse de acuerdo con su concepto lógico específico; de lo contrario lo que se revelaría no sería Dios. Él debe revelarse, pues, de acuerdo con su concepto, como un ser que afirma (sí) su ser o "así» como un puro ser infinito, y que niega (no) su nada y pone el ser infinito que él es a través de un acto infinito e incondicionado de libertad. Una libertad que pone un ser infinito es una libertad infinita; y una libertad infinita se puede identificar con el poder infinito. El concepto de Dios sólo puede ser configurado por el pensamiento como el de una vitalidad que tiene el poder de convertir su infinita libertad en infinita esencia. Si Dios efectivamente existe, en su revelación en la realidad efectiva deben reconocerse estas determinaciones incluidas en su concepto. Pues bien, en la realidad el «no», el renovado acto de poder infinito por el cual el concepto de Dios niega su nada, surge, pero ya no como «no», no como acto repentino de negación, sino como «sí», como afirmación sostenida de una propiedad infinita y constantemente duradera; y lo hace precisamente en el poder creador, que se extiende siempre y por doquier, y que se manifiesta en el hecho de que el mundo, que es siempre y por doquier, haya podido llegar a ser. Por ello, es decir, porque el poder infinito implica la posibilidad de llevar al ser todo lo que es, puede decirse que en la propia idea de Dios está augurada la Creación del mundo. Asimismo, la idea del mundo implica su creaturalidad. En efecto, el concepto formal o metalógico del mundo no puede garantizarle realidad efectiva al mundo real que está ya ahí, que ha acontecido y que acontece. Este mundo necesita que su existencia esté siendo constantemente creada y renovada. En una palabra, necesita consistencia, duración en el tiempo. Tiene, pues, que serle dada su existencia y su consistencia desde un ser fuera de su idea. Y en tanto ello ocurre, el mundo en su «ya-estar-ahí-dándose» se revela como creatura. En consecuencia, el mundo necesita ser creado y el poder creador no puede sino crear el mundo. Pero crear el mundo significa otorgarle consistencia y durabilidad, esto es, debe crearse el devenir a través del cual el mundo está una y otra vez llegando a ser lo que él es. Dicho brevemente: la creación del mundo es de suyo la creación del tiempo. El tiempo no es una forma vacía, que, como tal, no transcurre y en la cual el mundo transcurriría. Muy por el contrario, el tiempo es el transcurso mismo del mundo que comienza con la creación y que se despliega como el constante devenir de lo que es. No tiene sentido, pues, hablar de un «antes» o un «después» de lo que constituye el principio de toda realidad efectiva y de 
todo ser que pueda durar. «El principio está en el principio» ${ }^{5}$. $E l$ principio es: Dios creó» ${ }^{6}$. "Antes» del principio, antes de la Creación, no tiene sentido hablar de ninguna determinación temporal. Por ello mismo puede afirmarse que los instantes comienzan con la creación del mundo.

Sin embargo, tal cual asevera Rosenzweig, el mundo precede a todo presente. «El mundo existe antes de todo (...). Existe simplemente. Este ser del mundo es su Existir-ya, su Estar-ya-ahí. “¿Qué haces en el mundo? El mundo está ya hecho" » ${ }^{7}$. El «estar-ya ahí del mundo», el hecho de que el mundo nos está ya dado antes de cualquier acción y de todo acto de conciencia, lo conocemos como la nota decisiva de la temporalidad de la Creación: ella, respecto de todo presente actual, es ya pasada. Pero no lo es por haber ocurrido en el pasado, como si hubiese un fluir del tiempo independiente de la Creación y ella hubiera tenido lugar en él. Bien afirma Hans-Christoph Askani que «no es el pasado quien sirve para localizar aproximadamente a la Creación, sino que la Creación da el pasado - la Creación se da como pasado- (...)» ${ }^{8}$. Precisamente por ello su estructura temporal está determinada por la dimensión del pasado. Sin embargo, la Creación no es un pasado respecto del tiempo, como lo era la atemporalidad o perpetuidad de los conceptos de Dios, mundo y hombre, tal cual estos fueron analizados en la primera parte de La Estrella, sino que es el pasado de este presente en el que experimento constantemente el mundo y su renovarse. En tanto tal, es una de las dimensiones del presente. La Creación, específicamente, es el modo en que el existente experimenta en el presente el «estar-ya-ahí» del mundo, su permanente y constante «estar-ya-hecho», como la relación fundamental que vincula mundo con Dios. Si Estrella I mentaba la construcción conceptual y atemporal de tres totalidades ideales irrelativas, Estrella II mienta la experiencia presente de la revelación y temporalización en y como la única realidad efectiva de la existencia efectiva de Dios, del mundo y del hombre en su relación recíproca. El tiempo — que no contaba en el primer tomo- resulta para el segundo en un todo real, puesto que el revelarse de los elementos en su interrelación hace ser el tiempo mismo. No se trata aquí, empero, del tiempo "en el que» algo acontece, es decir, de una forma vacía y homogénea susceptible de medirse arbitrariamente en función de la relación entre dos movimientos regulares, sino del tiempo "que acontece por sí mismo»" ${ }^{9}$, esto es, del transcurrir de la realidad misma. Este transcurrir consiste precisamente de instantes, que, como resultado del milagro del estar aconteciendo continuamente la Creación, se dan de modo

\footnotetext{
ER, p. 179

ER, p. 155 .

ER, p. 175
}

8 Askani, Hans Ch., «Die Gestaltung der Zeit durch die Liturgie im Judentum und Christentum», en: Schmied-KowarziK, Wolfdietrich (ed.), Franz Rosenzweigs «neues Denken» - Band II: Erfahrene Offenbarung —in theologos, Alber, Freiburg/München 2006, pp. 956-981; aquí: p. 960.

9 Rosenzweig, F., El nuevo pensamiento, p. 29. 
tal que a la experiencia de uno se sucede la de otro diferente y no deducible del anterior.

Con lo arriba afirmado llegamos a la índole misma del darse del instante en el contexto de la Creación. Los instantes del mundo creado - los instantes del tiempo natural- constituyen la sucesión del renovarse del mundo. Ellos aseguran, como afirma G. Bensussan, «la construcción del puente lineal y horizontal del tiempo, sus encadenamientos, su flujo (...) $»^{10}$. En una palabra, la constante prosecución de su duración. Es igualmente cierto que, «una vez asegurado su oficio de continuación del tiempo por los medios del tiempo, los instantes recaen en su simple nada ${ }^{11}$. Ello es así porque, para expresarlo con las palabras del propio Rosenzweig, "cada momento tiene la certeza garantizada de que ya le llegará su turno - o sea, que puede estar tan seguro de que llegará a existir como puede estarlo un momento pasado de su haber ya existido- $\gg^{12}$. Sin embargo, no puede decirse de cada uno de estos instantes del tiempo natural, que están por existir o por dejar de hacerlo, "que se reduzcan a sí mismos, a su instantaneidad anodina y sin relieve» ${ }^{13}$. Tampoco puede describírselos diciendo que «constituyen el tiempo en una inmanencia que pone el instante por venir como ya contenido en el instante presente por simple iteración» ${ }^{14}$. En efecto, no puede caracterizárselos así, porque lo que determina la instantaneidad del instante en el tiempo natural no es ser un ahora cualquiera, inmanente a sí e idéntico a cualquier otro ahora en una progresión lineal. Muy por el contrario, lo que determina la instantaneidad del instante es el modo particular en que una y otra vez ha sido y continúa siendo recreada la Creación. Cada instante que sucede al otro, para luego hundirse en el pasado, corresponde a un estado particular del constante devenir a través del cual el mundo es recreado. El mundo no se da de un cierto modo a cada instante, sino que cada instante es un cierto modo de darse del mundo. Así concebido, el instante no es chato y anodino, sino que realiza la sucesión ininterrumpida, pero ya no de la uniformidad, sino de los distintos relieves del mundo. Lo que le da al instante su instantaneidad es precisamente este constante renovarse de la existencia: su permanente estar siendo recreada por Dios. En ese sentido

10 Bensussan, G., op. cit., p. 460.

11 Ibid.

12 ER, p. 276.

13 Bensussan, G., op. cit., p. 460.

14 Ibid. Bensussan, en su excelente artículo «Instant éthique et rason politique» realiza una magnífica descripción del instante mesiánico —el que interrumpe la continuidad del tiempo y anticipa la eternidad, anticipando un momento de justicia consumada- a través del análisis de su carácter indeterminable, discontinuo, disruptivo y denso. Sin embargo, para reforzar esta descripción opone el instante mesiánico a los pasajeros del tiempo natural, a los que interpreta, como es usual hacerlo, cual si fuesen «uniformes», «sin relieve», «reducidos a sí mismos», es decir, vacíos y meramente «iterativos». Considero que esta imagen estereotípica del mundo natural no le hace justicia al instante del mundo creado, porque estos instantes naturales, aunque se sucedan sin solución de continuidad, no son vacíos ni sin relieve, sino estados concretos del devenir del mundo. 
escribe Rosenzweig: «La existencia como tal, con su contante instantaneidad, exige de suyo estar siendo constantemente creada y renovada. Y así es como la toma en su mano el poder del Creador ${ }^{15}$. Y es que, para el filósofo de Kassel, «este tomar Dios la existencia en su mano no sucede en la Creación que tuvo lugar una vez para siempre, sino que es momentáneo ${ }^{16}$. En otros términos: la Creación «se renueva, respecto de toda la existencia, en cada mínimo instante particular, de modo que Dios "renueva día a día la obra del principio" ${ }^{17}$. Gracias a esta renovación, Dios hace ser también el instante como relieve del mundo y pone la posibilidad constante de un nuevo principio.

Pensado en el contexto de la Creación continua, el instante del tiempo natural muestra tres características esenciales. En primer lugar, es un indicio y una figura de la eternidad. Ciertamente el instante es lo pasajero. Pero apenas pasa resurge como un nuevo instante, asegurando la permanencia del tiempo. El renovado resurgir de los instantes implica, entonces, la experiencia de la constancia de la Creación: de su eternidad. En efecto, aunque la Creación a cada momento sea ya pasada, y aunque sus momentos se deslicen reiteradamente hacia el olvido, el mundo y el tiempo por ella creados siguen estando allí gracias al surgir inexorable del nuevo instante. Como bien afirma S. Mosès la Creación experimentada «como permanencia de lo que está-ya-ahí es es una de las tres modalidades en las cuales es vivenciada la eternidad ${ }^{18}$. Como esta vivencia se da gracias al instante y su persistente resurgir, puede decirse que en el orden de la Creación él es el modo en que la eternidad como pasado del estarya-ahí del mundo se hace presente ahora en el tiempo. Sin embargo, lo que hace del instante una vivencia de la eternidad no es el relieve del mundo que se presenta con cada momento, pues ese relieve, como todos los rostros del mundo, camina hacia el ocaso. La Creación lleva impreso el sello de la muerte y la transitoriedad. Pero, como observa R. Wiehl, «la muerte no es la última palabra de la Creación, porque la Creación misma contiene el presagio de un hoy y un mañana después del ayer y el anteayer» ${ }^{19}$. Y lo presagia precisamente en la experiencia del resurgimiento de los instantes y, por tanto, en la promesa de nuevos aconteceres del mundo. De allí que lo eterno del instante sea el hecho de su reiterabilidad o repetición. El instante nunca termina de pasar, porque, cuando pasa, siempre está resurgiendo en otro nuevo, que, como el anterior, es el surgimiento de una configuración del mundo. La repetición es esencial al instante. Pero esta repetición, reitero, no lo es de la particularidad del mundo que ha pasado para siempre. No es empírica, sino trascendental, en el preciso sentido de que la renovación de los instantes es la condición de posibilidad

15 ER, p. 165

16 Ibid. (Cursivas mías).

17 Ibid.

18 Mosès, S., op. cit., p. 109.

19 Wiehl, R., "Zeit und Zeiterfahrung im "neuen” Denken von Franz Rosenzweig», en: Schmied-KowarziK, W. (ed.), Franz Rosenzweigs "neues Denken»-Band I: Selbstbegrenzendes Denken: in Philosophos, pp. 299-311; aquí: p. 310. 
de un nuevo acontecer del mundo, en el que el existente pueda realizarse a sí mismo. Porque el tiempo natural da constantemente nuevos instantes, porque hay nuevas figuras del mundo, puede Dios a través de ellas revelársele al existente, llamándolo a realizar su existencia en ese mismo mundo. El instante de la Creación deviene, así, condición de posibilidad del de la Revelación.

\subsection{El sentido del instante en la Revelación}

Por Revelación en sentido estricto entiende Rosenzweig el acaecimiento actual de la relación entre Dios y hombre. La primera revelación, acontecida en la Creación, exige, para reactualizarse y evitar su caída en el ocultamiento de lo ya pasado, la irrupción de una segunda. Pero ésta ha de ser instantánea, acaeciente, presente: «una Revelación en el sentido más estricto» ${ }^{20}$. Es por ello que, así como cada instante de la Creación, estaba bajo el signo temporal del pasado, la Revelación lo está bajo el del presente. Ahora bien, ¿cómo llamar a este acto revelador a través del cual Dios a cada instante se dona por entero gratuitamente al hombre y deviene, así, fácticamente presente para él? Rosenzweig responde: «Es el amor a quien corresponden todas las exigencias que hemos formulado al concepto del Revelador: el amor del amante no de la amada. Sólo el amor del amante es entrega de sí renovada a cada instante; sólo él se dona a sí mismo en el amor ${ }^{21}$. Si en la Creación había emergido el no de Dios bajo el signo opuesto del sí, en la Revelación se hace presente el otro elemento constitutivo del concepto divino: su esencia infinita, pero lo hace ahora bajo el signo del no. Dios se manifiesta y niega una y otra vez su nada como «amor que se suscita a cada instante nuevo, amor siempre joven y siempre primero $»^{22}$. Desde una perspectiva confesional o teológica, este amor divino resulta claro: Dios revela su amor por el hombre en la Escritura y, para el creyente, se revela a cada instante en la interioridad de su alma, llamándolo por su propio nombre y haciéndole sentir su amparo y protección. ¿Pero cómo entenderlo desde una perspectiva filosófica pre- (y no «anti» ni «pro») confesional? En este punto comparto totalmente el modo en que Bernhard Casper interpreta el sentido de la Revelación estricta en La Estrella. Para el prestigioso comentarista, si puede afirmarse que Dios se revela a cada instante y a cada hombre, ello acontece porque en la realidad efectiva, que me es ahora dada, se manifiesta un Poder Otro respecto de mí como aquel Poder que hace ser esa realidad y la deja configurarse de tal modo que ella me llame o convoque a ex-poner-me y ser más que un sí mismo cerrado en sí. Cuando yo me animo (en sentido literal) a ser experimento lo siguiente:

Que yo sólo puedo exponerme e ir más allá de mí mismo porque soy interpelado por un otro que yo mismo. Esto, que no soy yo, me deja ser y por eso

$20 \quad E R$, p. 206.

$21 \quad E R$, p. 206.

$22 \quad E R$, p. 205. 
me puedo confiar a ello (...). Para esta experiencia, en la que yo experimento que a mí mismo me está enteramente permitido ser tenemos sólo una palabra: experimento amor. $^{23}$

Como este amor lo experimento a través de la manera en que la realidad dada me invita a ser, puede afirmarse, otra vez con Casper, que «la revelación que me deja ser mí mismo está siempre mediada por el mundo» ${ }^{24}$. ¿Y cómo recibe el sí mismo este renovado acto de amor divino? Volviéndose "alma amada» 25 . Sabiéndome amado a cada instante, el sí mimo se anima una y otra vez a comenzar conmigo mismo, a desplegar su vida en el mundo en armonía con todas las otras vidas. Precisamente cuando ello ocurre, emerge en la realidad efectiva aquel elemento del concepto de hombre de Estrella I (su voluntad libre que se obstinaba en negar que el hombre sea otra cosa que el «sí mismo» que él es), pero lo hace bajo el signo afirmativo del sí, como la humilde fidelidad de un alma siempre dispuesta a recibir el acto de amor divino y, consecuentemente, a ser más que "sí mismo» como respuesta a ese acto de amor.

Tal cual es fácil advertir, la temporalidad más propia de la revelación es el instante, pues el acto de amor es, por esencia, instantáneo y presente. No se apoya sobre ninguna esencia predeterminada, pues, si así fuera, estaría ya fijado y pertenecería ya siempre al pasado. Entonces «aquello que él instituye [y a través de lo cual se muestra A G-M], justamente el hecho de poder comenzar una y otra vez conmigo mismo, se habría perdido» ${ }^{26}$. El amor divino se da, pues, "como algo que acaba de nacer, algo que empieza tan sin pasado, tan totalmente surgiendo en el instante al que llena y sólo en él» ${ }^{27}$. ¿Cómo entender este instante que me hace nacer a la vida? Ante todo, él guarda una diferencia esencial con el de la Creación. No se trata aquí ya más de los instantes del mundo, de la sucesión del tiempo natural, sino de un instante específicamente humano: aquel en el que el hombre se experimenta a sí mismo vivo. En concreto lo hace en el modo de sentirse dotado de e im-pulsado hacia la posibilidad de comenzar consigo mismo y configurar su propia vida con la vida del mundo. Si el instante de la Creación se inscribía en la continua sucesión del tiempo físico, el de la Revelación lo hace en el de la temporalidad humana. En tanto tal, él no mienta cualquier ahora de los tantos que se suceden, sino un determinado acontecimiento ${ }^{28}$, que, como ahora disruptivo, se recorta del continuo. Este acontecimiento es vivido (temporalizado) por el sí mismo como la irrupción de un presente a partir del cual él puede comenzar a ser y a tener, por tanto, también pasado y futuro. Precisamente por darse a través de un acontecimiento determinado, el instante de la revelación es una oportunidad

CASPER, B., op. cit., p. 129.

Ibid., p. 131.

ER, p. 215.

CASPER, B., op. cit., p. 127.

ER, p. 205.

28 «Así, pues, el amor de Dios no es una propiedad, sino un acontecimiento (...)». ER, p. 209. 
de realizar plenamente mi vida, que se me da ahora, que no se ha dado antes, y que, del modo en que ahora se me da, no tiene por qué darse después ${ }^{29}$. Por ello puede decirse que "Dios ama es purísimo presente» ${ }^{30}$. Por ello también puede adjudicársele al instante de la Revelación una dimensión «kairológica» y correlacional. "Kairológica», porque el instante de la Revelación mienta una determinada oportunidad, un cierto ahora propicio para que yo pueda comenzar a ser y a configurar mi vida en el mundo. Como kairológico que es no está en mis manos hacer que ocurra el instante. No es posible forzar el amor de Dios. "No hay pregunta que tenga derecho a abordarlo» ${ }^{31}$. Sólo queda esperar a que les llegue a cada uno de los seres que Dios aún no ama su instante. Por ello exige fe. Pero, cuando el instante llegue, debe ser asumido como tal: debo advertir y realizar las posibilidades de vitalización que él me ofrece. Por ello también exige sabiduría. En tanto oportunidad asumida, el instante de la Revelación - como todo amor verdadero- es correlacional: nace en el acto de amor divino, pero se realiza sólo cuando la oportunidad que él propicia es recibida y asumida humildemente por el alma amada.

A pesar de que la significación del instante del acontecimiento decisivo en la Revelación es más densa que el continuo resurgir de los rostros del mundo en los instantes de la Creación, no se trata de fenómenos inconexos. Puede decirse incluso que el instante de la Creación es la condición de posibilidad del de la Revelación. En efecto, si en el mundo puede tener lugar un determinado acontecimiento, a través del cual Dios manifiesta ahora su amor por mí, ello se debe a que en ese mismo mundo se suceden los ahoras y, con ellos, los acontecimientos. En una palabra: a que la Creación es continua. La prosecución de los instantes en el tiempo da, pues, la posibilidad de que en uno de los momentos de la sucesión acaezca el instante que es vivido por el hombre como aquel en el que lo Absoluto se le revela.

Ahora bien, el instante de la Creación y el de la Revelación no sólo están conectados entre sí, en tanto uno es condición necesaria del otro, sino que comparten notas esenciales comunes. Ambos son figuras de la temporalización de la eternidad. Si el instante en la Creación representaba la forma en que la eternidad se temporalizaba como pasado; el de la Revelación es la figura que asume la eternidad como presente. Ello se debe a que «el amor de Dios está por entero en el momento y en el punto en el que ama ${ }^{32}$. Dicho esto mismo en términos no teológicos, ello se debe a que en el instante de la Revelación - y gracias al acontecimiento que lo instituye- el existente vislumbra el sentido entero de la vida y, por tanto, del lugar que su propia vida tiene en la totalidad de la vida. Desde entonces ese presente es uno que no pasa, sino que, para quien lo vive, permanece eternamente presente. Si se tiene en cuenta lo antedicho, se

29 «¿Qué sabe el amor de si amará? ¿Qué sabe, incluso, de si ha amado? Le basta con saber sólo una cosa: que está amando». ER, p. 209.

$30 \quad E R$, p. 209.

$31 \quad E R$, p. 209.

32 ER, p. 209. Cursivas mías. 
puede comprender mejor por qué S. Mosès incluye como uno de los tres modos en que es experimentada la eternidad en el tiempo a «la revelación vivenciada como eternización del instante presente « ${ }^{33}$. Pero el instante de la revelación no sólo guarda con el de la Creación la esencia común de ser ambos figuras de la temporalización de la eternidad, sino que también comparte con él sus notas esenciales de reiterabilidad y trascendentalidad. En efecto, no puede decirse que el acto de amor de Dios ocurra hoy y nunca más. ¿Quién puede exigirle al Señor de los cielos que no vuelva a amar? El instante de su acto de amor puede, pues, repetirse. Es cierto que Dios «ama siempre sólo al que ama y a aquello que ama ${ }^{34}$. Pero también lo es que lo único que separa su amor de quien no lo ha recibido —o de quien lo ha dejado pasar- es tan sólo un «aún no». A cada instante puede repetirse un acontecimiento que nos permita comenzar a consumar nuestra vida, porque el amor de Dios «anda por el mundo con ímpetu siempre nuevo ${ }^{35}$. Ciertamente la repetición del instante no tiene un sentido empírico. Los acontecimientos no se repiten en su materialidad. Pero sí trascendental. Lo que se repite, cuando se repite el amor de Dios, no es un determinado suceso, sino estar colocado ante la posibilidad de darle sentido y plenitud a mi vida. Este carácter trascendental del instante de la Revelación se realizará de modo pleno en la Redención, pero se deja advertir ya como sentido de la reiterabilidad del acto de amor divino. Quizás porque el amor de Dios es repetible, porque Él ofrece a todos una y otra vez la posibilidad de vitalizar la existencia, la propia y la de todo lo que es, puede decir Rosenzweig de este amor divino que «está siempre presente en el hoy, enteramente en el hoy; pero todos los ayeres y mañanas muertos se sumirán un día en este hoy triunfante» ${ }^{36}$.

\subsection{El sentido del instante en la Redención}

Por redención entiende Rosenzweig el acontecimiento de la relación entre hombre y mundo por la cual se anticipa en el presente la consumación del mundo como Reino. Al final de la Revelación nos encontrábamos con un sí mismo al cual el acto instantáneo de amor divino convertía en alma amada. Pero si ella responde al llamado a vivir sólo gozando de sentir que su propia vida es amada por Dios, corre el riesgo de cerrarse para el mundo que Dios le ofrece y adónde le insta a vivir. ¿Cómo se sale de este encierro místico del sí mismo en el alma amada? Se sale en cuanto el sí mismo abandona el éxtasis de sentirse amado por Dios y comienza a volcar la vida que le es ofrecida en la vida del mundo. Mas ello implica que se manifieste el constante "ser-así» implícito en el concepto de "sí mismo», a saber, su esencial particularidad finita o carácter, bajo el signo del no, esto es, como acto renovado de amor al prójimo. Pero si bien el amor al prójimo es un acto libre, la libertad no es

\footnotetext{
33 Mosès, S., op. cit., p. 109.

34 ER, p. 209.

35 ER, p. 209.

$36 \quad E R$, p. 209.
} 
suficiente para amar al prójimo. Es menester también tener amor, necesidad de amar y esperanza en que amar tiene sentido. Tal cosa no la puede producir la voluntad por sí misma: tiene que estarle dada. Por eso, al cumplimiento del mandato de amor al prójimo en la Redención, tiene que precederle, como su condición trascendental de posibilidad, aquel acto instantáneo por el cual Dios se revela en la Revelación, dándonos su amor como capacidad de $\operatorname{amar}^{37}$.

El mundo es el otro polo de la Redención. El acto de amor al prójimo está dirigido al mundo. El prójimo no es sino un representante suyo, pues es aquel que, en el instante del amor, está más próximo y mejor preparado para recibir el amor que se le ofrece. Por ello el acto de amor al prójimo recae sobre el mundo. ¿Cómo lo hace? Transformando el mundo creado, cuyos seres se muestran en su conjunto como incompletos, mutuamente enfrentados y corruptibles, en una totalidad armónica de seres consumados y perdurables. Ahora bien, para Rosenzweig, que la plétora de individuos que componen el mundo pueda consumar de forma armónica y perdurable la figura que tienen dentro de sí, implica poseer vida. Estar vivo significa conservar «la figura propia de uno mismo que se forma desde dentro de uno y que es, por ello mismo, necesariamente perdurable ${ }^{38}$. Pero a la vida que intenta afirmarse como esencia también le es esencial morir. En la realidad efectiva sólo encontramos la plétora fenoménica viviendo una vida finita y pasajera y no la infinita y perdurable que buscamos. ¿Cómo resolver esta aporía? Tomando en serio al tiempo. "[La contradicción se resuelve A G-M] con la sencilla idea de que lo que estamos buscando no es ya algo que hay ahí, sino algo que viene. Buscamos una vida infinita y encontramos una finita. Luego esta vida finita que encontramos no es más que la que todavía no es infinita. El mundo tiene que llegar a ser todo él viviente ${ }^{39}$. Tiene que consumarse. Tiene que llegar a ser un todo lleno de vida en el que cada una de las vidas ha alcanzado en armonía con las otras su figura más plena. Tiene que llegar a ser Reino. Como la afirmación de un Reino de Vida infinita ha de emerger, pues, la plétora fenoménica, que según el concepto del mundo de Estrella $I$ era lo que una y otra vez negaba que el mundo fuese nada Sin embargo, este Reino aún no ha emergido. Su llegada, empero, se puede anticipar ¿Cómo? Vitalizando la existencia, dando vida a todo lo que es; y dándola de modo tal que, por un instante (que emula la eternidad), cada vida sea no sólo compatible con las demás, sino que se consume en consonancia con ellas. En el acto instantáneo de amor al prójimo se anticipa hoy la futura llegada Reino o, lo que es lo mismo, la Redención. ¿Es esta anticipación definitiva? Nunca lo es, porque la eternidad se temporaliza sólo por un instante y la muerte jamás es del todo vencida. Mientras haya tiempo el Reino podrá ser a cada instante anticipado y estará, así, llegando.

37 «Únicamente el alma amada por Dios puede recibir el mandamiento del amor al prójimo con el fundamento de cumplirlo». ER, p. 262.

$38 \quad E R$, p. 271.

$39 \quad E R$, p. 274. 
Pero nunca acabará de llegar. «Siempre existe tanto como es futuro»" ${ }^{40}$ No existe aún de modo definitivo, pero viene constantemente. «La eternidad no es un tiempo larguísimo, sino un mañana que podría perfectamente ser también hoy ${ }^{41}$. Ese hoy es el instante en que, por obra de cada acto de amor, se anticipa la Redención. Sin esa anticipación, sin procurar adelantar, aunque más no fuera en la angostura de un instante, la consumación armónica de todas las vidas, el futuro no sería otra cosa que la inacabable prolongación extática de las miserias del pasado; no sería, en una palabra, verdaderamente futuro, sino sólo devenir. «Porque sin esa anticipación el instante no es eterno, sino que es algo que va perpetuamente arrastrado por la larga carretera general del tiempo ${ }^{42}$.

Si en la Creación el instante era esencialmente mundano y en la Revelación era fundamentalmente humano, ahora en la Redención el instante es básicamente divino. En efecto, el instante que anticipa la Redención futura deja que resplandezca por un momento el Reino, que es su Reino, que es Dios mismo. «En la Redención del mundo por el hombre y del hombre en el mundo, Dios se redime a sí mismo. El hombre y el mundo desaparecen en la Redención; Dios, en cambio, en ella se cumple ${ }^{43}$. El cumplimiento de la consumación armónica e imperecedera de todas las vidas ya no es meramente la prolongación pasajera del presente, el futuro de este tiempo, sino un auténtico futuro del tiempo, en el que la transitoriedad no tiene sentido, y que llamamos eternidad. Por ello mismo el instante que la anticipa - aquel en que un momento de plenitud de la vida deja resplandecer el Reino- se vuelve un hoy que es mucho más que hoy e incluso que mañana: un hoy traspasado de eternidad. El instante, que en la Creación era el modo o la figura en que la eternidad se temporalizaba desde el pasado como origen del mundo, y que en la Revelación lo era de esa misma temporalización de la eternidad, pero en el presente como alma del hombre, es ahora en la Redención el modo o figura en que la eternidad se temporaliza desde el futuro como anticipación del Reino de Dios.

Hemos dicho que el auténtico futuro no viene, pues, automáticamente, pues, si lo hiciese, «no sería otra cosa que la proyección del tiempo siempre pasajero en la dimensión de lo aún no realizado, y por tanto estaría igualmente determinado a pasar» ${ }^{44}$. Por eso mismo el instante de la Redención no puede ser esperado, sino que tiene que ser anticipado. Sin embargo, no puede ser anticipado a voluntad, sino que la anticipación debe ocurrir en el tiempo justo, que no es otro que aquel en que el acto de amor al prójimo recae en aquellos o aquello que está preparado para ser vitalizado. Es decir, debe ocurrir, como asevera Askani, en el «tiempo brindado (geschenkte Zeit)» para ello. Por eso mismo la naturaleza kairológica y correlacional del instante de la Revelación se reconoce también en el instante de la Redención. Él se da como la concordancia

$40 \quad E R$, p. 273.

41 ER, p. 273.

$42 \quad E R$, p. 276.

43 ER, p. 289

44 AsKani, H. C., op. cit., p. 961. 
de dos órdenes. Por un lado, el desarrollo natural del mundo creado. Por otro, los actos a través de los cuales el hombre realiza su existencia en él. La anticipación de la Redención tiene lugar cuando el hombre, realizando su existencia, toma sobre sí un momento de la evolución del mundo y lo vivifica, esto es, permite la configuración y realización de la mayor cantidad posible de potencialidades vitales latentes en ese momento. Pero, para ello, el mundo debe estar maduro para ser vivificado, esto es, debe requerir precisamente de los actos que realizan la existencia de ese hombre para vitalizarse. S. Mosès observa que «esta conjunción entre el orden del mundo y el del hombre, (...), es representada figurativamente a través del "y" que designa el instante de la Redención $»^{45}$. Yo agregaría que lo designa como correlación kairológica.

En tanto el instante de la Redención resulta de esta correlación kairológica entre la evolución del mundo y los actos del hombre resulta patente que él presupone como su condición tanto los instantes de la Creación, que acaece como devenir del mundo, cuanto el de la Revelación, a partir del cual el hombre comienza a actuar en el mundo. Pero si la condición trascendental de posibilidad del instante de la Redención lo son los otras dos estratos del instante, no es menos cierto que él es igualmente trascendental, porque es la condición de posibilidad de que el Reino no sea un futuro lejanísimo, desplazado hacia «quién-sabe- cuándo» en el final del tiempo, sino que esté constantemente viniendo. «El Reino, la vitalización de la existencia, viene desde el principio, y está siempre viniendo» ${ }^{46}$. Si ello puede ser así, es porque los actos de amor al prójimo que vitalizan el mundo son, más que actos, actitudes que se renuevan y repiten con cada acto, vitalizando hoy éste y mañana aquel otro rostro del mundo. Al instante de la Redención, para poder consumar su sentido como anticipación de una eternidad que «está siempre viniendo», le es esencial como a las otras dos figuras del instante, la repetición ${ }^{47}$.

\section{LA ETERNIZACIÓN DE LA TEMPORALIDAD}

Si tenemos en cuenta lo elucidado en el primer apartado, debemos concluir que lo que define el instante rosenzweiguiano es ser un lapso, que puede extenderse más o menos desde el punto de vista cronológico, pero en el que se

45 MosÈs, S., op. cit., p. 115.

$46 \quad E R$, p. 273.

47 Cabría preguntarse aquí hasta qué punto este carácter repetible del instante rosenzweiguiano no desemboca en la noción kierkegaardiana de repetición. El propio Rosenzweig señala a Kierkegaard como uno de los principales antecesores de la ruptura de la totalidad obrada en su obra capital. ¿Termina aquí la influencia de Kierkegaard o habría que extenderla a la concepción del instante? También para Kierkegaard el instante era el cruce de la eternidad con tiempo. Igualmente, para el danés, la repetición acontece como instante y es trascendental, toda vez que lo repetido no son los sucesos, sino la posibilidad de un nuevo comienzo y, con ella, la de un presente pleno de sentido. El desarrollo de esta cuestión excede, por supuesto, el espacio y objetivos de este artículo. 
entrecruzan el tiempo, comprendido como la sucesión de los ahoras del mundo, $y$ la eternidad, concebida como aquel ahora que no pasa, sino que está («estante») una y otra vez presente como él mismo en («in») el decurso del tiempo. En tanto el instante se hace una y otra vez presente, pertenece a su esencia la renovada reiterabilidad o repetición; y en la medida en que esta renovación hace posible en la Creación la Revelación, en la Revelación la Redención y en la Redención la vivencia anticipada del Reino, el instante es por naturaleza trascendental (en el específico sentido de condición de posibilidad). Si este entrecruzamiento asume distintas figuras y en cada una de ellas manifiesta estratos significativos diversos, ello se debe a que la eternidad está presente instantáneamente en el tiempo desde el pasado del mundo en la Creación, desde el presente del alma en la Revelación y desde el futuro del Reino en la Redención.

El entrecruzamiento de tiempo y eternidad (y, con él, el instante) no sólo puede resultar de la temporalización de la eternidad, sino de la eternización de la temporalidad. Comprender tal eternización exige pasar de Estrella II a Estrella III. Habremos de abandonar, pues, el mundo siempre renovado de la realidad efectiva y adelantarnos hacia el "supra-mundo» eterno del Reino, por cuya venida sólo podemos orar. El tiempo de la oración justa, a saber, de aquella en que la comunidad en su conjunto ama y vitaliza lo que está listo para ser vitalizado, hace del hoy —nos dice Rosenzweig — lo más próximo a la eternidad ${ }^{48}$. ¿Pero cómo es posible afirmar que un hoy fugitivo puede eternizarse? ¿De qué manera la oración logra hacer que su momento, pasajero y volátil, permanezca? Y debe permanecer, pues la eternidad es, precisamente, lo que no pasa. Rosenzweig responde: «El instante que buscamos, al pasar volando, tiene, en el mismo instante, que empezar ya de nuevo; al hundirse ha de estar ya levantándose otra vez. Su pasar tiene simultáneamente que ser un renacer ${ }^{49}$. No basta, pues, para que el tiempo se eternice, que vuelva otro instante, sino que tiene que regresar el mismo instante. El instante que buscamos no ha de ser, entonces, un Augen-blick ${ }^{50}$, una "ojeada», que descubre siempre algo nuevo. Antes bien, se trata de un "nunc stans», esto es, de un verdadero "in-stante» que siempre "está aquí» («estante»), aunque el tiempo pase. «Tal ahora estante (stehend) se llama, a diferencia del instante-ojeada [Augen-blick], hora, Stunde» ${ }^{51}$. Aunque pueda resultar sorprendente, en la hora encuentra Rosenzweig una figura de la eternización el tiempo. En efecto, la hora siempre vuelve como una hora. Su fin desemboca de nuevo en un principio, y entre principio y fin tiene un medio, que contiene la riqueza de los instantes pasajeros. Dotada de principio,

48 Cf. $E R$, p. 245.

49 ER, p. 346.

50 El término alemán para instante, «Augen-blick», se halla compuesto por Auge (ojo) y Blick (vista). Significa literalmente «mirada», vistazo o, como bien traduce García-Baró, «ojeada».

51 Stunde (hora) en alemán es una construcción con alternancia vocálica derivada del verbo medio alto alemán «standen», del que procede también el verbo «stehen», que tiene precisamente el significado de «estar quieto». 
medio y fin, la hora llega a ser lo que nunca podrá ser la mera sucesión de momentos particulares: «un círculo que vuelve y gira sobre sí» ${ }^{52}$. Por eso, cuando una hora termina, "no empieza meramente una nueva hora, (...), sino que empieza otra vez una hora $»^{53}$. Nada sabe el mundo ni la Creación de horas. La hora no es un ciclo celeste. Es una institución por entero humana y social: la introducción de una imagen de la eternidad en el tiempo. En efecto, sólo fijando un período, tal cual ocurre en la hora, «se hace perceptible la repetición que sucede en el recorrido del círculo» ${ }^{54}$. Y es esa repetición rítmica lo que vuelve a ciertos intervalos de tiempo horas, y a esas horas "fiadoras» ${ }^{55}$ (Bürgen) de la eternidad. Pero como «imagen» humana y como «garante» la hora sólo asegura la posibilidad de la eternidad. Para que el tiempo efectivamente se eternice es preciso que lo que se repita rítmicamente en la hora sea la oración justa: aquella en que la comunidad se reúne para vivificar el mundo y anticipar el Reino, que es lo verdaderamente eterno. Sólo así la hora (o la semana, que para Rosenzweig es otra imagen de la etenidad,) «no se limita a introducir en el hoy lo eterno de manera meramente figurativa, sino en realidad ${ }^{56}$. Por eso la hora como efectiva eternización del tiempo sólo ocurre con relación a la Redención $\mathrm{y}$ «mienta el ritmo conforme al cual acaece su irrepresentable temporalizarse como futuro del presente (...) $»^{57}$. El tiempo se eterniza, pues, realmente en la hora como in-stante ${ }^{58}$, como nunc stans, cuando el instante de la oración de la comunidad repite rítmicamente la anticipación de la Redención. Tal cosa, para Rosenzweig, se da por antonomasia en el culto. «En la repetición cotidiana, semanal y anual de los círculos de la oración cultual, la fe hace del instante hora, hace que el tiempo se vuelva acogedor para la eternidad $\aleph^{59}$.

Si esto es así, pareciera que la eternización del tiempo está limitada a las comunidades de culto confesionales, en particular el judaísmo y el cristianismo.

\begin{tabular}{ll}
\hline 52 & $E R$, p. 346. \\
53 & $E R$, p. 346. \\
54 & $E R$, p. 347. \\
55 & $E R$, p. 347. \\
56 & $E R$, p. 348.
\end{tabular}

57 NavarRete, R.,. Los tiempos del poder. Franz Rosenzweig y Carl Schmitt, Escolar y Mayo, Madrid 2017, p. 235.

58 José M. Cuesta considera que esta exégesis rosenzweiguiana del instante como hora implica una neutralización «de la distinción temporal entre el ser y el ente». Cuesta, J. M., La escritura del instante. Una poética de la temporalidad, Aka, Madrid 2001, p. 267. Además, el estar al que se aferra la hora sería una versión neutral del ser, por lo que comprender el instante como «estante» significa remitirlo a «una temporalidad suspendida en y de un Es gibt o Il y a» (Ibid.). Me permito disentir por dos razones. Primero, hay que recordar que el «instantehora» anticipa la Redención, y la Redención es, para Rosenzweig, aquel «entre» en que se encuentran y consuman su ser Dios, mundo y hombre. Precisamente en tanto encuentro de la totalidad de lo que es en la consumación relacional de su ser, la hora anticipa la temporalidad del ser y la distingue de la del mero ente considerado en sí mismo. En segundo, porque, en tanto anticipación de una consumación de la configuración de la vida, la temporalidad del instante de ninguna manera queda suspendida de un vacío Il y a.

$59 \quad E R$, p. 348. 
De hecho, Rosenzweig lo da a entender de esta manera, pues Estrella III analiza el culto judío como vida eterna en el tiempo, y el cristiano como eterno camino hacia el Reino. Sin embargo, ¿es esto necesariamente así? Parecía claro que tanto el instante de la Creación, como el de la Revelación y el de la Redención, tal cual aquí fueron interpretados, le permitían a todo hombre en tanto tal experimentar en ellos lo Absoluto. En efecto, es propio de todo humano advertir en la magnificencia de los rostros del mundo y en el curso indetenible del tiempo lo Absoluto dado en la Creación. A nadie le está privado volver a encontrarse con ese Absoluto en aquel acontecimiento decisivo que le revela el sentido de la vida y de la suya propia. Y no es necesario ser judío o cristiano para amar al prójimo y anticipar la armonía de todas las vidas. No le es necesaria, pues, a la eternidad una confesión para temporalizarse. Pero sí pareciera serlo para que podamos eternizar al tiempo. Permítaseme concluir apartándome de una interpretación literal de Estrella III y plantear la siguiente pregunta: ¿Es el ciclo cultual de una determinada confesión quien vuelve la hora del culto un instante que anticipa la eternidad o es la reiterada anticipación de la eternidad lo que hace de una hora compartida un instante eterno y un culto? Si lo segundo es cierto, toda comunidad humana - sea o no judía, sea o no cristiana- que sienta el ímpetu de la vida hacia lo Absoluto y, de la mano de ese ímpetu, recomience a cada instante el cotidiano trabajo de configurar, potenciar y vivificar el mundo, está volviendo ese modesto instante uno eterno. Si lo segundo es cierto, nada nos impide, pues, pensar que cada amanecer puede ser, para todos, la aurora de la eternidad.

\section{BibLIOGRAFÍA}

Askani, H. Ch. (2006). «Die Gestaltung der Zeit durch die Liturgie im Judentum und Christentum», en: SchmiedKowarzik, Wolfdietrich (ed.), Franz Rosenzweigs «neues Denken» - Band II: Erfahrene Offenbarung —in theologos. Freiburg/München: Alber, pp. 956-981.

Bensussan, G. (2006). «Instant éthique et raison politique», en: SchmiedKowarzik, Wolfdietrich, Franz Rosenzweigs «neues Denken» - Band I: Selbstbegrenzendes Denken: in Philosophos. Freiburg/München: Alber, pp. 459469.

Casper, B. (2017). Das dialogische Denken. Franz Rosenzweig. Ferdinand Ebner und Martin Buber. Freiburg/München: Aber, p. 3.

Cuesta, J. M. (2001). La escritura del instante. Una poética de la temporalidad. Madrid: Aka1.

Froman, W. J., «Rosenzweig and Heidegger on "the moment" ("der Augenblick")», en: SchmiedKowarzik, Wolfdietrich (ed.), Franz Rosenzweigs «neues Denken»-Band I: Selbstbegrenzendes Denken: in Philosophos, pp. 228-246.

García-Baró, M. (1997). «Introducción», en: Rosenzweig, Franz, La Estrella de la Redención. Salamanca: Sígueme, pp. 11-39.

Garrido Maturano, Á. (2000). La Estrella de la Esperanza. Introducción a La Estrella de la Redención de Franz Rosenzweig desde una perspectiva fenomenológica. Buenos Aires: Academia Nacional de Ciencias. 
Mosès, S. (1985). System und Offenbarung. Die Philosophie Franz Rosenzweigs. München: Wilhelm Fink.

Navarrete, R. (2017). Los tiempos del poder. Franz Rosenzweig y Carl Schmitt. Madrid: Escolar y Mayo.

Rosenzweig, F. (1997). La Estrella de la Redención, trad. M. García Baró. Salamanca: Sígueme.

Rosenzweig, F. (2005). El nuevo pensamiento, trad. A. GarridoMaturano. Buenos Aires: Adriana Hidalgo.

Wiehl, R. «Zeit und Zeiterfahrung im “neuen” Denken von Franz Rosenzweig», en: SchmiedKowarzik, W (ed.), Franz Rosenzweigs «neues Denken»-Band I: Selbstbegrenzendes Denken: in Philosophos, pp. 299-311.

\section{CONICET}

Ángel EnRiQue Garrido-Maturano

Instituto de Investigaciones Geohistóricas, Resistencia

Argentina

hieloypuna@hotmail.com

[Artículo aprobado para publicación en febrero de 2020] 